Retraction

\title{
Retracted: Intrathecal Pump Implantation in the Cisterna Magna for Treating Intractable Cancer Pain
}

\author{
Case Reports in Anesthesiology
}

Received 7 July 2021; Accepted 7 July 2021; Published 11 August 2021

Copyright (c) 2021 Case Reports in Anesthesiology. This is an open access article distributed under the Creative Commons Attribution License, which permits unrestricted use, distribution, and reproduction in any medium, provided the original work is properly cited.

Case Reports in Anesthesiology has retracted the article titled "Intrathecal Pump Implantation in the Cisterna Magna for Treating Intractable Cancer Pain" [1] due to concerns with the reliability of the data. The authors identified that incorrect images were used in Figure 1 due to an error in the storage and image selection by the authors during manuscript preparation. The authors explained to the journal that the reliability of the results presented cannot be guaranteed, and the article is, therefore, being retracted with the agreement of the authors and the editorial board.

\section{References}

[1] Y. Lou, Y. Rao, and Z. Feng, "Intrathecal Pump implantation in the Cisterna Magna for treating intractable cancer Pain," Case Reports in Anesthesiology, vol. 2018, Article ID 5287150, 5 pages, 2018. 